\title{
Pattern of Adverse Drug Reactions Due to Cancer Chemotherapy in a Tertiary Care Teaching Hospital in Eastern India
}

Anju Prasad ${ }^{1}$, Pratyay Pratim Datta ${ }^{1 *}$, Jibak Bhattacharya ${ }^{2}$, Chaitali Pattanayak ${ }^{1}$, Ashok Singh Chauhan $^{1}$ and Parbaty Panda ${ }^{1}$

${ }^{1}$ Department of Pharmacology, Hi-Tech Medical College and Hospital, Bhubaneswar, India

${ }^{2}$ Department of Radiotherapy, NRS Medical College and Hospital, Kolkata, India

\begin{abstract}
Introduction: Adverse drug reactions (ADRs) are a global problem adding to the economic burden of the society. Anti-cancer drugs are prone to cause ADRs and there is lack of pharmacovigilance data on such drugs. Therefore the present study was undertaken to monitor suspected ADRs in the radiotherapy unit of a tertiary care teaching hospital in Eastern India.

Materials and methods: The present study was done in the Radiotherapy Department of a tertiary care teaching hospital in Eastern India from March, 2012 to August, 2012 among the patients receiving cancer chemotherapy. It was a hospital based prospective observational study. ADRs were documented in Suspected Adverse Drug Reaction reporting form designed by Centre for Drug Standard Control Organizationand causality assessment was done using Naranjo scale.

Results: $87 \%$ of the total patients receiving cancer chemotherapy developed ADRs. Most common ADRs found were nausea and vomiting followed by neutropenia. Cisplatin, Cyclophosphamide, 5-Fluoro uracil, Paclitaxel and Adriamycin were common drugs causing ADRs. $62 \%$ of the ADRs were probable according to Naranjo scale.

Conclusion: The cancer chemotherapeutic drugs are associated with varied adverse effects. However, early detection of drug toxicity helps to modify the doses or the drug regimen to minimize toxic effects.
\end{abstract}

Keywords: Adverse drug reactions; Pharmacovigilance; Cancer chemotherapeutic drug; Cisplatin; Naranjocausality assessment scale

\section{Introduction}

An adverse drug reaction (ADR) is defined by World Health Organization (WHO) as "Any response to a drug which is noxious, unintended and occurs at doses used in man for prophylaxis, diagnosis or therapy" [1]. It has been seen that healthcare cost increases to a great extent due to Adverse Drug Reactions (ADRs) [2]. Sometimes the ADRs are so serious and severe that, cost needed to treat morbidity and mortality due to it, is more than the cost needed to treat the actual condition of interest [3]. With the dramatic advances in the medical science, treatment of many cancers (like testicular cancer, lymphoma, and leukemia) is not palliative, but rather curative in today's world. Chemotherapy is employed as part of a multimodal approach to the treatment of many tumours [4]. The acute effects of frequent administration of anti-neoplastic drugs includes nausea-vomiting, via a central mechanism and sometimes extremely severe [5]. Many of the adverse effects of anti-neoplastic are an extension of their therapeutic action, which is not selective for malignant cells but affects all rapidly dividing cells; anti-neoplastic therapy is made possible only by increased sensitivity or less effective recovery of malignant cells compared with normal cells [5].

Cancer chemotherapeutic drugs very often show ADRs. Nausea, vomiting, myelosuppression, mucositis etc. are very common ADRs due to cancer chemotherapy [6]. If ADRs due to cancer chemotherapy is compared to the development of total ADRs, then also it shows a very high percentage as revealed in one study from South India [7].

Compromising dose intensity of cancer drug therapy by delaying or reducing doses can compromise outcomes of therapy. The dosage regimen and the method of administration can greatly affect their efficacy and toxicity [8]. There is paucity of data regarding the safety profile of cancer chemotherapy in Eastern India. So, the objective of the present study was to evaluate the pattern of ADRs occurring in cancer patients treated with chemotherapy in a tertiary care hospital in Eastern India.

\section{Materials and Methods}

\section{Study area}

The study was carried out in the Department of Radiotherapy, HiTech Medical College and Hospital, Bhubaneswar, Odisha, India. It is a tertiary care teaching hospital situated in Eastern India. It runs a separate Radiotherapy Department supported by a separate ward, outpatient department and radiotherapy set-up. Most common cancer in the state of Odisha is oro-pharyngeal carcinoma.

\section{Study period and study population}

The study was conducted from March, 2012 to August, 2012. The patients admitted in the department of Radiotherapy and treated with anti-neoplastic drugs during the study period were included in the present study.

${ }^{*}$ Corresponding author: Pratyay Pratim Datta, P.G. Resident, Department of Pharmacology, Hi-Tech Medical College and Hospital, Bhubaneswar, Flat 301, Bipasa Apartment, 24/1/A S.S. Sen Road, Berhampore, Murshidabad, West Bengal, PIN742101, India, Tel: +91-9433457247; E-mail: pratyaypratimdatta@gmail.com

Received January 24, 2013; Accepted February 06, 2013; Published February 08, 2013

Citation: Prasad A, Datta PP, Bhattacharya J, Pattanayak C, Chauhan AS, et al. (2013) Pattern of Adverse Drug Reactions Due to Cancer Chemotherapy in a Tertiary Care Teaching Hospital in Eastern India. J Pharmacovigilance 1: 107 doi:10.4172/2329-6887.1000107

Copyright: (C) 2013 Prasad A, et al. This is an open-access article distributed under the terms of the Creative Commons Attribution License, which permits unrestricted use, distribution, and reproduction in any medium, provided the original author and source are credited. 
Citation: Prasad A, Datta PP, Bhattacharya J, Pattanayak C, Chauhan AS, et al. (2013) Pattern of Adverse Drug Reactions Due to Cancer Chemotherapy in a Tertiary Care Teaching Hospital in Eastern India. J Pharmacovigilance 1: 107. doi:10.4172/2329-6887.1000107

Page 2 of 4

\section{Study design}

It was a hospital based prospective observational study. The patients were followed up for a period of one month after they had received the cancer chemotherapeutic drugs.

\section{Inclusion and exclusion criteria}

Among the patients receiving chemotherapy, those who developed at least one ADR, were included in the study. The patients who did not show any ADR except alopecia were excluded from the study.

\section{Study tools}

Adverse drug reaction reporting form designed by Centre for Drug Standard Control Organization (CDSCO) was used to collect the data regarding ADRs. One separate questionnaire regarding sociodemographic characteristics was developed and used in the study. To assess the causality, Naranjo Causality Assessment Scale was used [9].

\section{Statistical analysis}

After collection of data, it was double entered in Microsoft Excel sheet and validated. One clean datasheet was generated and copied into SPSS (version 16.0). Then the analysis was done in SPSS (version 16.0).

\section{Results}

In the study period, 52 patients in the radiotherapy in patient department received chemotherapeutic agents for the treatment of their malignant conditions. Among these 52 patients, 45 (86.53\%) developed adverse drug reaction due to any chemotherapeutic agent. Only 7 patients did not have any problem except alopecia after taking chemotherapy regimen. As alopecia has no physical problem (only the psychological and social problems), so this adverse effect was not considered in the present study. Our present study deals with the adverse drug reaction pattern among these 45 patients (Table 1).

Table 2 describes the socio-demographic characteristics of the study population. It was found that among these 45 patients, 24 (53\%) were male and remaining $21(47 \%)$ were female. Most common age group was found to be between $50-59$ years $(42 \%)$. Only 5 persons (11\%) were aged below 40 years. 8 (18\%) patients were between $40-49$ years, $7(16 \%)$ patients were between $60-69$ years and $6(13 \%)$ patients were 70 years and above. Among these 45 patients, 32 (71.11\%) were married at the time of presentation to the hospital. 9 (20\%) patients were widowed and rest four (8.89\%) patients were never married. Socioeconomic status was assessed using modified Kuppuswami scale [10]. It was found that $8.89 \%$ patients were from upper socio-economic status and another $8.89 \%$ patients were from upper middle class. Most of the study population (32.22\%) belonged from upper lower socio-economic status. $20 \%$ of the study population belonged from each group of lower middle class and lower class.

Figure 1 showsthedistribution of cancersfor whichchemotherapeutic drugs were used which caused adverse drug reactions. Bronchogenic

\begin{tabular}{|l|c|}
\hline \multicolumn{1}{|c|}{ Patients } & Number \\
\hline $\begin{array}{l}\text { Patients receiving chemotherapeutic } \\
\text { agents }\end{array}$ & 52 \\
\hline $\begin{array}{l}\text { Patients developing adverse drug } \\
\text { reactions }\end{array}$ & 45 \\
\hline $\begin{array}{l}\text { Percentage of patients developing } \\
\text { adverse drug reactions }\end{array}$ & $86.53 \%$ \\
\hline
\end{tabular}

Table 1: Patients developing adverse drug reaction after receiving cancer chemotherapy.

\begin{tabular}{|c|c|c|c|}
\hline \multicolumn{2}{|c|}{ Variable } & Number & Percentage \\
\hline \multirow{4}{*}{ Sex } & Male & 24 & 53.33 \\
\cline { 2 - 4 } & Female & 21 & 46.67 \\
\hline \multirow{4}{*}{ Age } & Less than 40 years & 5 & 11.11 \\
\cline { 2 - 4 } & $40-49$ years & 8 & 17.78 \\
\cline { 2 - 4 } & $50-59$ years & 19 & 42.22 \\
\cline { 2 - 4 } & $60-69$ years & 7 & 15.56 \\
\cline { 2 - 4 } & 70 years and & 6 & 13.33 \\
\hline \multirow{4}{*}{ Marital status } & above & & 71.11 \\
\cline { 2 - 4 } & Married & 32 & 8.89 \\
\cline { 2 - 4 } & Never married & 4 & 20.00 \\
\cline { 2 - 4 } Socio-economic & Widowed & 9 & 8.89 \\
\hline \multirow{3}{*}{ status* } & Upper & 4 & 8.89 \\
\cline { 2 - 4 } & Upper middle & 4 & 20.00 \\
\cline { 2 - 4 } & Lower middle & 9 & 32.22 \\
\cline { 2 - 4 } & Upper lower & 19 & 20.00 \\
\cline { 2 - 4 } & Lower & 9 & \\
\hline
\end{tabular}

*Socio-economic status was evaluated in modified Kuppuswami scale

Table 2: Socio demographic characteristics of the study population.

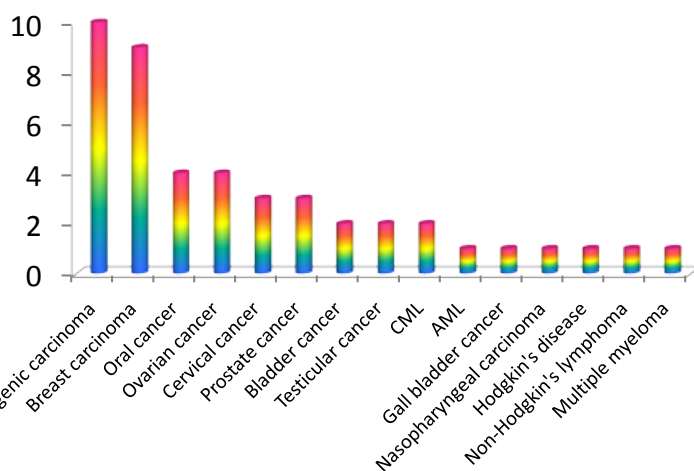

Figure 1: Distribution of cancers.

carcinoma was found to be most common cancer in this set up followed by breast carcinoma. Oral cancer and ovarian cancer were seen in four patients each. Three patients had cervical carcinoma and three patients had prostate cancer. Bladder cancer, testicular cancer and chronic myeloid leukemia (CML), these were seen among two patients each. Acute myeloid leukemia (AML), gall bladder cancer, nasopharyngeal carcinoma, Hodgkin's disease, Non-Hodgkin's lymphoma (NHL), and multiple myeloma were experienced by one patient each.

Figure 2 shows the pattern of adverse drug reactions developed among the patients. Most common adverse drug reaction experienced was nausea and vomiting (developed among 16 patients). Neutropenia was found to be second most common adverse drug reaction experienced by 12 persons. Other adverse drug reactions were less common. Anaemia was developed among four patients; three patients experienced skin rash; three patients experienced hepatotoxicity; two patients had acute renal failure; another two patients suffered from severe diarrhea. Only one patient has acute stomatitis. Tingling and numbness was seen in one patient. Rare finding like cerebellar ataxia was experienced by one patient.

Figure 3 shows the distribution of drugs according to the number of adverse drug reactions produced. Cisplatin was most common drug which caused adverse drug reactions in 13 patients. Cyclophosphamide was second most common drug. It caused adverse drug reactions in 11 


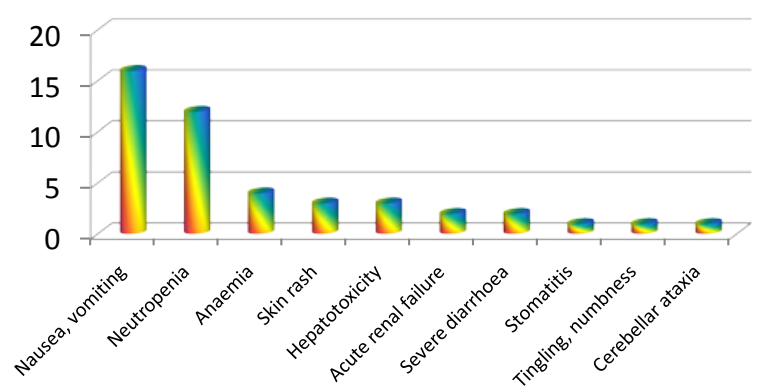

Figure 2: Pattern of adverse drug reactions developed.

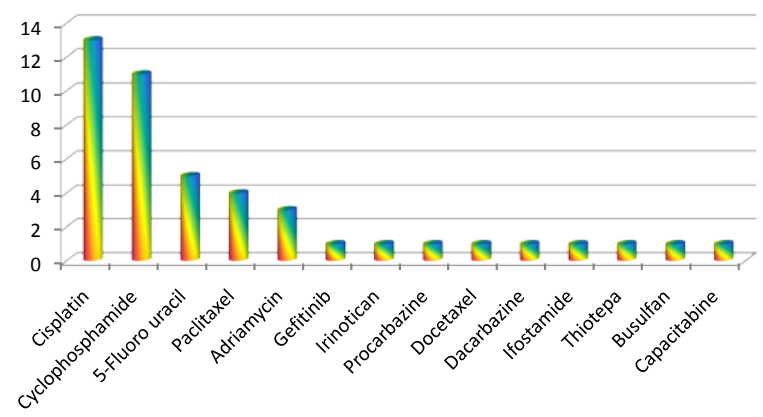

Figure 3: Drugs responsible for adverse drug reactions.

patients. After receiving 5-fluoro uracil (5-FU) five patients had adverse drug reactions. Four adverse drug reactions after taking Paclitaxel and three adverse drug reactions were seen after receiving Adriamycin. Gefitinib, Irinotican, Procarbazine, Docetaxel, Dacarbazine, Ifostamide, Thiotepa, Busulfan and Capacitabine-these were responsible for development of adverse drug reaction in one patient each. Causality assessment was done for each adverse drug reactions by Naranjo's Causality Assessment Scale (Table 3). It was found that $3(7 \%)$ of the adverse drug reactions fell into definite category. 28 (62\%) adverse drug reactions were in probable category and $14(31 \%)$ adverse drug reactions were in possible category.

\section{Discussion}

Our study identified the pattern of ADRs caused by cancer chemotherapeutic agents in a tertiary care teaching hospital of Eastern India. In our study $86.53 \%$ of the patients receiving anti-neoplastic drugs developed ADRs. In the present study males were found to have more number of ADRs as compared to females though the difference was not significant. This is comparable to study conducted in a tertiary care hospital in Nepal by Mallik et al. [11]. On the contrary according to a study by Blacker et al. in 1993 ADRs were found to be more common in the female population [12]. However, another study identified no difference between men and women in the incidence of ADRs [7].

Patients aged 50-59 years encountered majority of the ADRs. Only five patients (11.11\%) under 40 years developed ADRs. In general the incidence of ADRs is higher in elderly patients as found in other studies $[7,11]$. The reason could be that in elderly patients, the metabolizing capacity and the excretory functions are generally diminished leading to accumulation of drugs in the body and thus increasing the risk of ADRs [13].

In the present study majority (71.11\%) of the patients were married.
This finding corroborates with the finding by Poddar et al. [14], the pattern of incidence of cancer differs according to socio-economic status of patients. In our study most common socio-economic class affected was upper lower class (32.22\%). Only 4 (8.89\%) patients were from upper class [14]. As the majority of patients admitted in the hospital are from lower or upper lower class, that's why most common affected groups were from these classes. Another study from Bangladesh has found that majority of patients developing adverse reactions from antineoplastic drugs were from upper-middle class [14].

Most common cancer in our study was found to be bronchogenic carcinoma followed by breast carcinoma. 4 patients $(8.89 \%)$ had cervical carcinoma and 4 patients $(8.89 \%)$ had oral carcinoma. In India most common cancer among males is oro-pharyngeal cancer followed by bronchogenic carcinoma. Among females most common cancer in India is cervical cancer followed by breast cancer.

Nausea and vomiting were found to be commonest ADRs in our patients. In other studies also these were found to be the commonest ADRs [14]. The most common mechanism of chemotherapy induced nausea and vomiting is through activation of Chemoreceptor Trigger Zone (CTZ) [15]. Since vomiting is a common problem associated with cancer chemotherapy, strategies should be made to prevent and manage the vomiting in patients undergoing cancer chemotherapy.

Next common ADR was found to be neutropenia. In other study by Mallik et al. neutropenia was found to be commonest ADR [11]. While destroying cancer cells, chemotherapy can also damage rapidly dividing cells of bone marrow resulting in myelosuppression thus affecting white blood cells (WBC), platelets and red blood cells (RBC).

Anaemia was found in four patients in our study. Anaemia due to chemotherapy induced myelosuppression usually occurs 2-3 weeks after the administration of chemotherapy and can be managed by blood transfusion and erythropoietin.

Cisplatin was responsible for $29 \%$ of the total ADRs. The ADRs associated with the use of Cisplatin are nausea, vomiting, myelosuppression, peripheral neuropathy, ototoxicity and nephrotoxicity. Elderly patients are at higher risk of myelosuppression, nephrotoxicity and neurotoxicity due to Cisplatin (Klasco) [16]. Cyclophosphamide, 5-fluoro uracil, Paclitaxel and Adriamycin were found to be other important drugs to cause ADRs. Cisplatin and these four drugs were very commonly used for the treatment of cancer. So, they resulted in development of maximum number of ADRs in our study. Causality assessment of ADRs was done using Naranjo's scale. $62 \%$ ADRs were found to be probable, $31 \%$ ADRs were possible and near about $7 \%$ were definite ADRs. Re-challenge test was positive in definite ADRs.

\section{Conclusion}

$87 \%$ of the patients attending the Radiotherapy Department and receiving cancer chemotherapy developed ADRs. Male patients and patients belonging to the age group 50-59 years had a higher incidence of ADRs. ADRs occurred most commonly in the married people and who belonged to upper lower socio-economic status. Bronchogenic

\begin{tabular}{|l|c|c|}
\hline Causality assessment & Number & Percentage \\
\hline Definite & 3 & 6.67 \\
\hline Probable & 28 & 62.22 \\
\hline Possible & 14 & 31.11 \\
\hline
\end{tabular}

Table 3: Causality assessment of adverse drug reactions according to Naranjo's Causality assessment scale. 
Citation: Prasad A, Datta PP, Bhattacharya J, Pattanayak C, Chauhan AS, et al. (2013) Pattern of Adverse Drug Reactions Due to Cancer Chemotherapy in a Tertiary Care Teaching Hospital in Eastern India. J Pharmacovigilance 1: 107. doi:10.4172/2329-6887.1000107

Page 4 of 4

carcinoma was the commonest cancer encountered followed by breast cancer. Nausea and vomiting are the commonest ADRs reported. Cisplatin was the common drug causing the ADRs. Our study was one of its kinds in providing a baseline data regarding the safety profile of cancer drugs in a teaching hospital in Eastern India.

\section{References}

1. Lee A, Thomas SHL (2003) Adverse drug reactions. In: Clinical Pharmacy and Therapeutics Roger. (3rdedn), Churchill Livingstone, Spainp 33-34.

2. Nerurkar RP, Nadkar MY, Bichile SK (1998) Need for monitoring adverse drug reactions. J Assoc Physicians India 46: 673-674.

3. Smith DL (1993) The effect of patient non- compliance onhealth care costs. Med Interface 6: 74-84

4. Chabner BA, Amrein PC Druker BJ (2006) Antineoplastic agents: Goodman and Gilman's The Pharmacological Basis of Therapeutics. (11thedn), The MaGraw-Hill Companies, Inc., USA.

5. Sweetman SC (2002) Martindale: The Complete Drug Reference. (33rdedn), Pharmaceutical Press. London, UK.

6. Beers MH, Berko R (1999) The Merk manual of Diagonosis and Therapy. (17thedn), Merck Publishing Group, USA.

7. Jose J, Rao PG (2006) Pattern of adverse drug reactions notified by spontaneous reporting in an Indian tertiary care teaching hospital. Pharmacol Res 54: 226-233.
8. Dipiro J, Talbert RL, Yee GC, Matzke GR, Wells BG, et al. (2005) Pharmacotherapy: A Pathophysiologic Approach. (6thedn), McGraw-Hil Companies, Inc., USA.

9. Zaki SA (2011) Adverse drug reaction and causality assessment scales. Lung India 28: 152-153.

10. Kumar N, Gupta N, Kishore J (2012) Kuppuswamy's socioeconomic scale: Updating income ranges for the year 2012. Indian J Public Health 56: 103-104.

11. Mallik S, Palaian S, Ojha P, Mishra P (2007) Pattern of adverse drug reactions due to cancer chemotherapy in a tertiary care teaching hospital in Nepal. Pak J Pharm Sci 20: 214-218.

12. Blacker K, Stern R, Wintroub BU (1993) Cutaneous reactions to drugs, Dermatology in General. McGraw-Hill, New York, USA.

13. Bates DW, Leape L (2000) Adverse drug reaction, Morreli's Clinical Pharmacology. (4thEdn), McGraw-Hill, Boston, USA.

14. Poddar S, Sultana R, Sultana R, Akbor MM, Azad MAK, et al. (2009) Pattern of Adverse Drug Reactions Due to Cancer Chemotherapy in Tertiary Care Teaching Hospital in Bangladesh. The Dhaka University Journal of Pharmaceutical Sciences 8: 11-16.

15. Stewart DJ, Kucharczyk J, Miller AD (1991) Nausea and vomiting: recent research and clinical advances. CRC Press, Boca Raton, USA.

16. Klasco RK (2006) DRUGDEX® System. Micromedex, Greenwood Village Colorado. 